\title{
Transitioning from emergency remote teaching to quality online delivery: an Irish professional development perspective
}

\author{
Darina M. Slattery \\ University of Limerick
}

Keywords: emergency remote teaching; professional development; quality; online teaching; training; technology.

\section{The challenge}

As was the case in most higher education institutions, the University of Limerick (UL) moved to emergency remote teaching overnight in March 2020. As an academic who specialises in online education and runs professional development workshops in that area, I wanted to help colleagues who were unprepared for online teaching. As $\mathrm{UL}$ is predominantly an on-campus institution, anyone who was not already teaching online was faced with a steep learning curve, while also dealing with health concerns, working from home, and possibly home schooling. In addition to not being ready, some staff were not enthusiastic about teaching online (Cutri et al., 2020).

About a year before the pandemic, UL established an informal community of practice called the Learning Technology Forum (LTF), of which I am a member. Once the pandemic started, we (the LTF) started planning professional development (PD) initiatives that would help staff transition from face-to-face delivery to remote teaching, in a matter of days. Some members of the LTF offered to run workshops on specific tools, whereas others focussed on the pedagogy of teaching online. While our first challenge was to help staff become comfortable with remote teaching in spring 2020, our second challenge was to help them develop better quality online courses (Hodges et al., 2020), for the 2020/21 academic year. 


\section{The response}

Before the pandemic, I had been delivering two-day on-campus workshops on how to design and develop online programmes (Slattery, 2021). This workshop had been designed for small programme teams and was not scalable for an entire university. Once the pandemic began, I decided to customise the workshop into two 2.5-hour webinars, to facilitate online participation. The first webinar covered course planning and design, and the second covered course delivery and evaluation. Revamping an interactive face-to-face workshop into two webinars proved challenging, partly because I had to omit content that I would normally cover. I also had a much larger audience and therefore could not customise the content to any particular discipline. Nonetheless, the webinars covered essential topics that anyone new to online teaching should consider, such as:

- how to write learning outcomes,

- how to align assessment with outcomes,

- how to choose appropriate technology,

- how to facilitate online activities, and

- how to evaluate the quality of an online course.

(Gagné et al., 2004; Salmon, 2013; Sheffield Hallam University, 2014; Slattery, 2021; SUNY, 2018).

The LTF offered most of the live training in July 2020 and posted all the recorded sessions online to facilitate asynchronous viewing. Good attendance figures and engagement during my two webinars (over 150 bookings for the live events and over 160 asynchronous viewings) suggest that participants valued the fact that I am an online teacher, as well as a subject-matter expert. As anxiety about using technology is often a factor in reluctance to use technology (Johnson et al., 2012), I also made sure to talk about the challenges I encounter as an online teacher, to reassure attendees that issues are normal, and to be expected.

As we approached the autumn semester, we learned through informal feedback that many staff still felt overwhelmed, some staff had developed bad practices, and others did not know which training resources to consult. One solution we devised 
was to develop a new blog series addressing some strategies and practices that staff found particularly challenging, while also directing readers back to the training resources we developed earlier in the year. I contributed a three-part blog posting, which outlined the following tried-and-trusted strategies for ensuring quality online delivery (Slattery, 2020):

- use tools consistently and effectively,

- use synchronous tools when you need to facilitate two-way interaction,

- engage students on a regular basis,

- break larger groups into smaller groups,

- offer guidance and supplementary resources,

- encourage students to log in every day, and do the same yourself,

- be clear about expectations,

- avoid information overload, and

- organise the forums.

My blog posting had the highest overall viewings (1,607 combined page views) when compared with the other blog postings in the series. The other blog postings covered other useful topics, including how to promote academic honesty, how to create a visually appealing Virtual Learning Environment (VLE) site, and how to improve student-teacher communication online.

\section{Recommendations}

While the anecdotal and email feedback we have received about our recent PD initiatives has been very positive, we now need to consider how we can meet the ongoing needs of colleagues and students. As I write this article, we have just finished the spring 2021 semester, which mostly took place online. Given the prevailing number of cases nationally and the possible emergence of new COVID-19 variants, we are being advised to plan for on-campus delivery in autumn 2021, but also to be prepared for online delivery, should the need arise. As we have already developed a substantial repository of training resources, we have decided to focus our summer 2021 training schedule on the following areas:

- showcasing 'What's new?' in supported tools and technologies, 
- upskilling people who might not have taught since the start of the pandemic,

- upskilling people who might have developed poor online practices during the pandemic,

- upskilling people about the importance of accessibility and Universal Design for Learning,

- facilitating curriculum design, and

- facilitating improved student engagement.

In the first half of 2021 , I led the consultation phase of a campus wide VLE review, to identify and acquire a new VLE for UL. Once we reach the VLE adoption phase, we plan to use the new VLE to bring everyone on board-not just the innovators and early adopters, but also those who are still reluctant to use technology (Rasheed et al., 2020; Rogers, 2003). We will demonstrate how their recently developed skills will serve them well as they adapt to new technologies, and that pedagogy should always drive technology use, not the other way around (Boettcher \& Conrad, 2016). We will use survey data gathered during the VLE review to identify training gaps and technology requirements. For example, staff are requesting training in multiple formats (including print), better collaboration tools, VLE templates to ensure consistency, and better VLE integration with tools such as Microsoft Teams. Cutri et al (2020) refer to the 'sparked enthusiasm' caused by the forced move online. If there is any upside to the pandemic from a teaching and learning point of view, it is that more people are now aware of the affordances that technology can facilitate in teaching and learning (Limperos et al., 2015).

\section{References}

Boettcher, J. V., and Conrad, R.-M. (2016) The online teaching survival guide. $2^{\text {nd }}$ edn. San Francisco, CA: Jossey-Bass.

Cutri, R. M., Mena, J. and Whiting, E. F. (2020) 'Faculty readiness for online crisis teaching: Transitioning to online teaching during the COVID-19 pandemic', 
European Journal of Teacher Education 43(4), pp, 523-541.

DOI: 10.1080/02619768.2020.1815702 (Accessed: 3 August 2021).

Gagné, Robert M., Wager, Walter W., Golas, Katherine C., and Keller, John M.

(2004) Principles of instructional design. 5th edn. Belmont, CA: Wadsworth.

Hodges, C., Moore, S., Lockee, B., Trust, T., and Bond, A. (2020) The difference between emergency remote teaching and online learning. Available at: https://er.educause.edu/articles/2020/3/the-difference-between-emergencyremote-teaching-and-online-learning (Accessed: 3 August 2021).

Johnson, T., Wisniewski, M. A., Kuhlemeyer, G., Isaacs, G., and Krzykowski, J. (2012) 'Technology adoption in higher education: Overcoming anxiety through faculty bootcamp', Journal of Asynchronous Learning Networks, 16(2), pp. 6372. Available at: https://files.eric.ed.gov/fulltext/EJ971045.pdf (Accessed: 3 August 2021).

Limperos, A. M., Buckner, M. M., Kaufmann, R., and Frisby, B. N. (2015) ‘Online teaching and technological affordances: An experimental investigation into the impact of modality and clarity on perceived and actual learning', Computers \& Education, 83, pp. 1-9. Available at: https://doi.org/10.1016/j.compedu.2014.12.015 (Accessed: 3 August 2021).

Rasheed, R. A., Kamsin, A., and Abdullah, N. A. (2020) 'Challenges in the online component of blended learning: A systematic review', Computers \& Education, 144, pp. 1-17. Available at: https://doi.org/10.1016/j.compedu.2019.103701 (Accessed: 3 August 2021).

Rogers, E. M. (2003) Diffusion of innovations. $5^{\text {th }}$ edn. New York: Free Press.

Salmon, G. (2013) E-tivities: The key to active online learning, $2^{\text {nd }}$ edn. London and New York: Routledge. 
Sheffield Hallam University (2014) Teaching approaches menu. Available at: https://tinyurl.com/y5b27In3 (Accessed: 3 August 2021).

Slattery, D. M. (2021) DUO workshop overview. Available at: https://staff.ul.ie/slatteryd/sites/default/files//DUO Workshop Overview.pdf (Accessed: 03 August 2021).

Slattery, D. M. (2020) '9 Tried-and-trusted strategies for quality online delivery’, Quick Tips for Teaching Online [online], available: https://www.ul.ie/ltt/newscentre/news/quick-tips-teaching-online-9-tried-and-trusted-strategies-qualityonline-delivery (Accessed: 3 August 2021).

SUNY (2018) The SUNY online course quality review rubric OSCQR, 3rd edition (2018). Available at: https://oscar.suny.edu/ (Accessed: 3 August 2021).

\section{Author details}

Darina Slattery is a senior lecturer at the University of Limerick (Ireland), where she teaches graduate courses on e-learning and instructional design and runs professional development workshops for faculty in the area of online programme development. She is President of the IEEE Professional Communication Society (ProComm) and an alumna of the Institute for Emerging Leadership in Online Learning (IELOL). Darina's research interests include online learning/ e-learning, virtual teams, learning analytics, and the professional development of online teachers. 